\title{
Pressure sensor calibrations of acoustic telemetry transmitters
}

\author{
Maxime A. N. Veilleux ${ }^{1 *}$, Nicolas W. R. Lapointe ${ }^{1}$, Dale M. Webber ${ }^{2}$, Tom R. Binder ${ }^{3}$, Paul J. Blanchfield ${ }^{4}$, \\ Liset Cruz-Font ${ }^{5}$, Mathew G. Wells ${ }^{5}$, Martin H. Larsen ${ }^{6}$, Susan E. Doka ${ }^{7}$ and Steven J. Cooke
}

\begin{abstract}
Background: Acoustic transmitters are widely used to obtain information on the spatial ecology of fish and other aquatic animals. Some transmitters contain pressure sensors to estimate depth, which are factory-calibrated before being sold and have a specified range of error. Our goal was to assess the accuracy of these pressure sensors and the factory calibrations to assess whether researchers should conduct additional calibrations prior to use in the field. To evaluate error, we conducted calibrations on ten acoustic transmitters with pressure sensors (obtained from VemcoAmirix Ltd.) both in the laboratory (pressure chambers at Hammond Bay Biological Station and Carleton University) and in the field (based on lowering tags to known depths in Toronto Harbour and Experimental Lakes Area). Slopes, intercepts, and $R^{2}$ values of researcher-calibrated sensors were compared to the factory-calibrated values to contrast calibration methods and identify directional biases. To estimate the effects of temperature on sensor performance, we calibrated the same sensors at varying temperatures and compared slopes, intercepts, and $R^{2}$ values. Finally, we evaluated external effects (i.e., water temperature, salinity, and atmospheric pressure) on sensor output through simple modeling exercises to better understand potential sources of error.

Results: A significant difference was found among the slopes and $R^{2}$ values of the four calibration events, whereas no difference was found among the intercepts. There was also a significant effect of calibration water temperature on slopes, intercepts, and $R^{2}$ values. External effects should be taken into consideration when interpreting biological data as they have an effect on hydrostatic pressure thereby affecting the reported depths $(1.77 \mathrm{~m}$ shallower to $6.47 \mathrm{~m}$ deeper than standard conditions).
\end{abstract}

Conclusions: Nonetheless, we did not find sufficient evidence to support the need for additional calibrations beyond those provided by the manufacturer as they did not markedly increase the accuracy of depth estimates.

Keywords: Acoustic telemetry, Calibration, Depth, Pressure, Sensor tags

\section{Background}

Biotelemetry enables researchers to study the behavior of fish and other aquatic animals in their natural environment $[11,4]$. Acoustic transmitters, in conjunction with acoustic hydrophones and receivers, have become exceptionally common for studying fish in marine and freshwater systems [9]. In particular, such tools can facilitate the study of fish behavior and habitat use across a variety of

\footnotetext{
*Correspondence: maximeveilleux7@gmail.com

${ }^{1}$ Fish Ecology and Conservation Physiology Laboratory, Department of Biology, Carleton University, 1125 Colonel By Drive, Ottawa, ON K1S 5B6, Canada

Full list of author information is available at the end of the article
}

spatial (from ocean basin to localized patches) and temporal (from days to years) scales $[6,10]$. The addition of sensors to electronic transmitters creates an opportunity to obtain additional information on animal-environment interactions [3]. The inclusion of pressure sensors in acoustic transmitters allows researchers to study diel vertical migrations [7], vertical distributions [14, 5], and depth selection $[2,8]$, which are important components of fish behavior and habitat use in aquatic three-dimensional landscapes [15].

Transmitters containing pressure sensors are typically factory-calibrated before being sold to researchers. For example, Vemco-Amirix, a vendor of acoustic telemetry 
equipment, calibrates every pressure sensor in roomtemperature fresh water in a pressure chamber, and the sensor measurement circuitry is adjusted to provide the same slope and intercept for each transmitter of a given batch. Values obtained from these calibrations are used to convert sensor output into depth estimates. Given that all Vemco transmitters from a single batch have the same slope and intercept, researchers may opt to perform additional calibrations to obtain unique values for each transmitter [14]. In theory, these additional calibrations should increase the accuracy of depth estimates. Calibrations are typically performed in the body of water where the study will occur, whereby transmitters are lowered to known depths in the water column (i.e., field calibrations), but can also take place in a pressurized chamber (i.e., laboratory calibrations). Although field calibrations can be performed at a low cost, they can be time-consuming and are subject to error from water movement (e.g., waves, vessel movement, currents) and water temperature (for e.g., transmitters calibrated in stratified lakes can experience a range in water temperature of $10{ }^{\circ} \mathrm{C}$ from surface waters to deeper waters). In contrast, laboratory calibrations require less time and are presumably more accurate, but do require access to a pressure chamber. Regardless of the calibration method, the extent to which these additional calibrations increase the accuracy of depth estimates is unknown. Moreover, it is unclear how external factors (e.g., salinity, water temperature, and atmospheric pressure) influence pressure sensor performance, which is relevant to calibrations and interpretation of field data. Indeed, these external factors may introduce greater error than the differences between factory- and researcher-calibrated transmitters.

Given uncertainty regarding factory calibrations, our first objective was to assess differences between factory and researcher calibrations. Our second objective was to evaluate external effects (salinity, water temperature, and atmospheric pressure) on sensor output. We also tested whether researcher calibrations helped to improve the accuracy of sensors, and quantified the amount of error associated with environmental factors, irrespective of calibration accuracy. We used a combination of laboratory calibrations and field calibrations from two freshwater lakes to achieve our first objective and used laboratory calibrations for our second objective. Given that most researchers do not have easy access to a pressure chamber for calibration, we also describe the construction and operation of a simple and inexpensive pressure chamber that can be used to simulate depths up to $140 \mathrm{~m}$.

\section{Methods}

\section{Laboratory and field calibrations}

Ten V16P-6H acoustic transmitters with pressure sensors (from Vemco: maximum depth $=68 \mathrm{~m}$, accuracy $= \pm 3.4 \mathrm{~m}$, resolution $=0.3 \mathrm{~m}$ ) were first calibrated in a pressurized chamber at Hammond Bay Biological Station (HBBS; Millersburg, MI). Transmitters were then surgically implanted into adult Lake Trout (Salvelinus namaycush) or Walleye (Sander vitreus) that were released into Lake Huron for a period of 23-351 days before being recaptured and returned by commercial or recreational fishers. (The implantation of the transmitters in fish was incidental to this study). Returned transmitters were then calibrated via an additional laboratory calibration and two field calibrations.

Post-recapture laboratory calibrations were performed at Carleton University (Ottawa, ON) using a different pressure chamber than was used for pre-deployment calibrations at HBBS (Fig. 1). The two pressure chambers were constructed identically from $10-\mathrm{cm}$ diameter, schedule-40 PVC (PolyVinyl Chloride) pipe (1.2 m long), which was sealed on the bottom end with a PVC cap. The top end of the PVC tube was capped with a $20-\mathrm{cm}$ $y$-fitting (schedule 40 PVC) containing a Banjo cam-lever cap (Alsco Industrial Products, Inc.) for accessing the chamber, a Tel-Tru stainless steel pressure gauge (Tel-Tru Manufacturing Company; model 33: 0-30 PSI), an airfilling valve, and a release valve for controlling and monitoring pressure within the chamber. The chambers were $3 / 4$ filled with room-temperature water, and an acoustic receiver (Vemco, model VR2W) was placed in the bottom of the chamber to record transmissions. A maximum of six transmitters were suspended near the water surface inside the chamber at one time to limit the frequency of transmitter signal collisions. The chamber was then sealed, and pressure was increased to 21 psi (equivalent

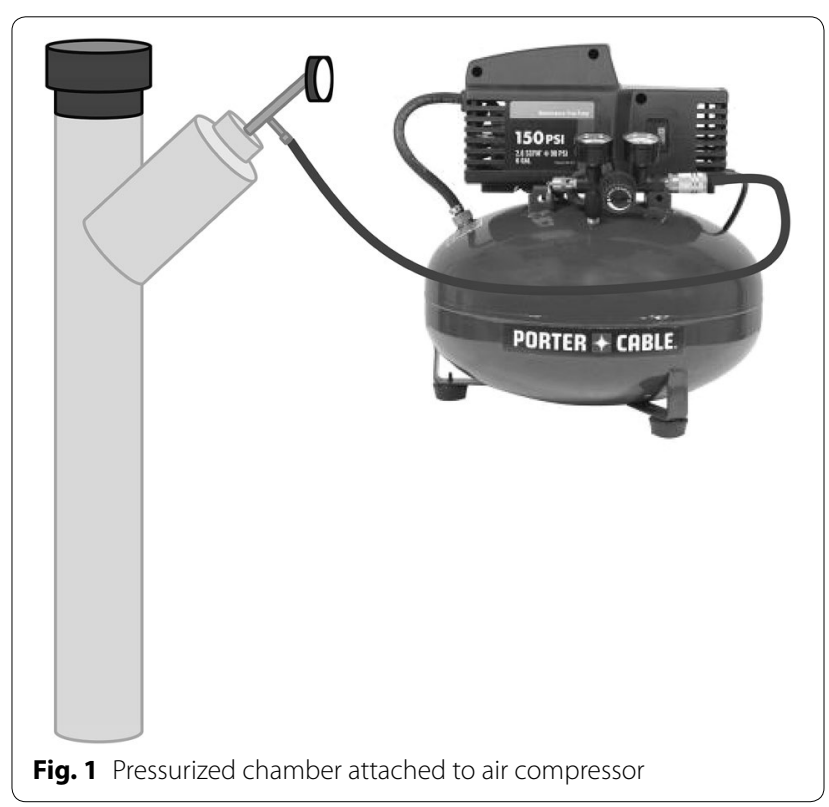


to the pressure at a depth of $14.8 \mathrm{~m}$ in fresh water at sea level) using a 6-gallon 150-psi pancake electric air compressor. The pressure was maintained at $21 \mathrm{psi}$ for $10 \mathrm{~min}$, and then decreased to $16 \mathrm{psi}$ for another $10 \mathrm{~min}$. These steps were repeated for pressures of 11,6 , and 0 psi (i.e., 7.75, 4.23, and $0 \mathrm{~m}$ ). A more powerful air compressor with a maximum pressure of $200 \mathrm{psi}$ can be used to simulate a depth of $140 \mathrm{~m}$, although appropriate safety protocols should be used to ensure safety of operators.

Field calibrations were conducted in Toronto Harbour (Toronto, ON) and Lake 373 within the Experimental Lakes Area (ELA) (Kenora, ON) with a mobile acoustic receiver (Vemco, model: VR100) and an omnidirectional hydrophone. At ELA, calibrations took place in a small $(4.7 \mathrm{~m})$ aluminum boat tied to a center buoy permanently anchored at the deepest part of the Lake $373\left(Z_{\max }=21 \mathrm{~m}\right.$; see [1] for details). Calibrations in Toronto Harbour were performed similarly; however, the maximum depth was only $12 \mathrm{~m}$. Individual transmitters were placed in a mesh bag and attached to a rope that was marked every meter and kept vertical by a heavy weight. The rope was lowered to a depth of $1 \mathrm{~m}$ for a few minutes until the reported depth was determined with the receiver (the hydrophone remained at the same depth, just below the surface of the lake). Transmitters were then lowered to increasing depths (i.e., 2, 5, 10, 15, $20 \mathrm{~m}$ ) and reported depths were recorded at each step. Field calibrations were conducted on calm days to ensure that the rope remained vertical. Field calibrations were also conducted during the fall of 2012 when lakes were not stratified (water temperatures ranged from $7{ }^{\circ} \mathrm{C}$ at the surface to $5^{\circ} \mathrm{C}$ at a depth of $20 \mathrm{~m}$ ).

Calibration curves were constructed for each tag under each calibration scenario. Transmitted sensor values (raw values recorded by the receivers called Analog to Digital Converter; ADC) were plotted against actual (field-based) or simulated (lab-based) transmitter depths. A line of best fit was plotted for each transmitter, and the slope, intercept, and $R^{2}$ values of the relationship between depth and sensor value were calculated (using Microsoft Office Excel 2007). To determine the degree of difference from actual or simulated depth, we calculated the difference between depths estimated using the factory-derived slope and intercept, and depths estimated using researcher calibration slopes and intercepts, up to a maximum simulated depth of $68 \mathrm{~m}$.

\section{Calibrations at three different water temperatures}

To evaluate the effects of temperature on sensor output, transmitters were calibrated at three different biologically relevant temperatures; cold $\left(9^{\circ} \mathrm{C}\right)$, cool $\left(20^{\circ} \mathrm{C}\right)$, and warm $\left(34{ }^{\circ} \mathrm{C}\right)$. Transmitters were calibrated in the laboratory at Carleton University, following procedures described above. Slopes, intercepts, $R^{2}$ values, and the degree of difference between obtained and actual depths were calculated as above.

\section{Quantifying error from temperature-driven changes in water density}

To calculate the effect of water temperature on depth estimates derived from pressure sensor values, the following equation was used: $P_{\text {total }}=P_{\text {atmosphere }}+P_{\text {fluid }} \cdot P_{\text {fluid }}=\rho g h$, where $P_{\text {atmosphere }}=$ atmospheric pressure $(\mathrm{Pa}), \rho=$ water density $\left(\mathrm{kg} / \mathrm{m}^{3}\right), g=$ gravitational acceleration $\left(9.8 \mathrm{~m} / \mathrm{s}^{2}\right)$, and $h=$ depth (m). For all evaluations of external effects on depth estimates, depths of $68 \mathrm{~m}$ (maximum depth of V16 transmitters) were used because errors would be most pronounced here (i.e., because changes in water density are cumulative with depth). The hydrostatic pressure of fresh water at three different water temperatures was calculated; $4{ }^{\circ} \mathrm{C}$ represents the temperature at which water has the highest water density (i.e., $999.9720 \mathrm{~kg} / \mathrm{m}^{3}$ ), $20{ }^{\circ} \mathrm{C}$ represents the default water temperature used for factory calibrations, and $40{ }^{\circ} \mathrm{C}$ was chosen because most natural bodies of water do not exceed this temperature. A transmitter located at $68 \mathrm{~m}$ in $20^{\circ} \mathrm{C}$ fresh water should sense a total pressure of 766,530.2781 Pa. To determine the maximum error associated with temperature-driven changes in water density, we calculated the corresponding depths at which the same transmitter would register 766,530.2781 Pa in both 4 and $40^{\circ} \mathrm{C}$ fresh water. The difference in calculated depth among the three temperatures reflects the sensitivity of the sensor to temperature-driven changes in water density.

\section{Quantifying error from salinity-driven changes in water density}

We calculated the effect of salinity-driven changes in water density on depth estimates in the same manner as above for temperature (i.e., $P_{\text {total }}=P_{\text {atmosphere }}+P_{\text {fluid }}$ ). A transmitter located at a depth of $68 \mathrm{~m}$ in $20{ }^{\circ} \mathrm{C}$ fresh water $\left(998.2072 \mathrm{~kg} / \mathrm{m}^{3}\right)$ senses a total pressure of $766,530.2781 \mathrm{~Pa}$. We calculated the depth at which the same transmitter would sense $766,530.2781 \mathrm{~Pa}$ in full strength salt water (35\%o salt; $\left.1024.8103 \mathrm{~kg} / \mathrm{m}^{3}\right)$. The difference in calculated depth between freshwater and sea water reflects the sensitivity of the sensor to salinitydriven changes in hydrostatic pressure.

\section{Quantifying error from changes in atmospheric pressure}

We calculated the effect of atmospheric pressure-driven changes in water density on depth estimates in the same manner as above (i.e., $P_{\text {total }}=P_{\text {atmosphere }}+P_{\text {fluid }}$ ). We calculated the total pressure of fresh water at three different atmospheric pressures; 87,000 $\mathrm{Pa}$, representing an extremely low but observed atmospheric pressure; 101,325 Pa, representing the standard atmospheric 
pressure; and 108,000 $\mathrm{Pa}$, representing an extremely high but observed atmospheric pressure. A transmitter located at a depth of $68 \mathrm{~m}$ in $20{ }^{\circ} \mathrm{C}$ fresh water senses a total pressure of $766,530.2781 \mathrm{~Pa}$. To determine the maximum error associated with atmospheric pressure-driven changes in water density, we calculated the corresponding depths at which the same transmitter would register $766,530.2781 \mathrm{~Pa}$ in both 87,000 and $108,000 \mathrm{~Pa}$ atmospheric pressures. The difference in calculated depths among the three atmospheric pressures reflects the sensitivity of the sensor to changes in atmospheric pressure.

\section{Statistical analysis}

Differences among slopes, intercepts, and $R^{2}$ values from the four calibration methods (i.e., HBBS, Carleton, Toronto, and ELA) were evaluated using three separate linear mixed-effects models (LMEs). Each model included the response variable (i.e., slope, intercept, or $R^{2}$ ) with calibration method as a fixed factor and transmitter identification number as a random effect variable to account for the repeated measures on each transmitter. The models were fitted using restricted maximum likelihood (REML). The analysis on $R^{2}$ data included the variance structure VarIdent to take into account differences in variance among the four calibration methods (see [16]. LMEs were also used to compare differences among slopes, intercepts, and $R^{2}$ values from calibrations performed in the three different water temperatures (i.e., cold, cool, and warm). When a significant effect of calibration method or calibration temperature was found, Tukey honestly significant difference (HSD) test was employed to investigate difference among groups.

All analyses were conducted in R version 3.1.2 [13] using the "nlme" package [12]. Prior to the analyses, data explorations were applied following a protocol described by [17]. The models were validated to verify that the underlying statistical assumptions were not violated. Homogeneity of variance was assessed by plotting residual versus fitted values, normality of residuals was evaluated by plotting theoretical quantiles versus standardized residuals (Q-Q plots), and independence was examined by plotting residuals versus the explanatory variable. $R^{2}$ data were arcsine transformed prior to analysis. One transmitter was excluded from all analysis and deemed defective as it reported erroneous data. Statistical significance for all analyses was set at $p<0.05$.

\section{Results}

\section{Laboratory and field calibrations}

There was a significant effect of calibration event on slope (LME; $F=54.670, d f=3, p<0.0001$ ) (Fig. 2). Slopes obtained from Carleton University calibrations were significantly greater than slopes obtained from the

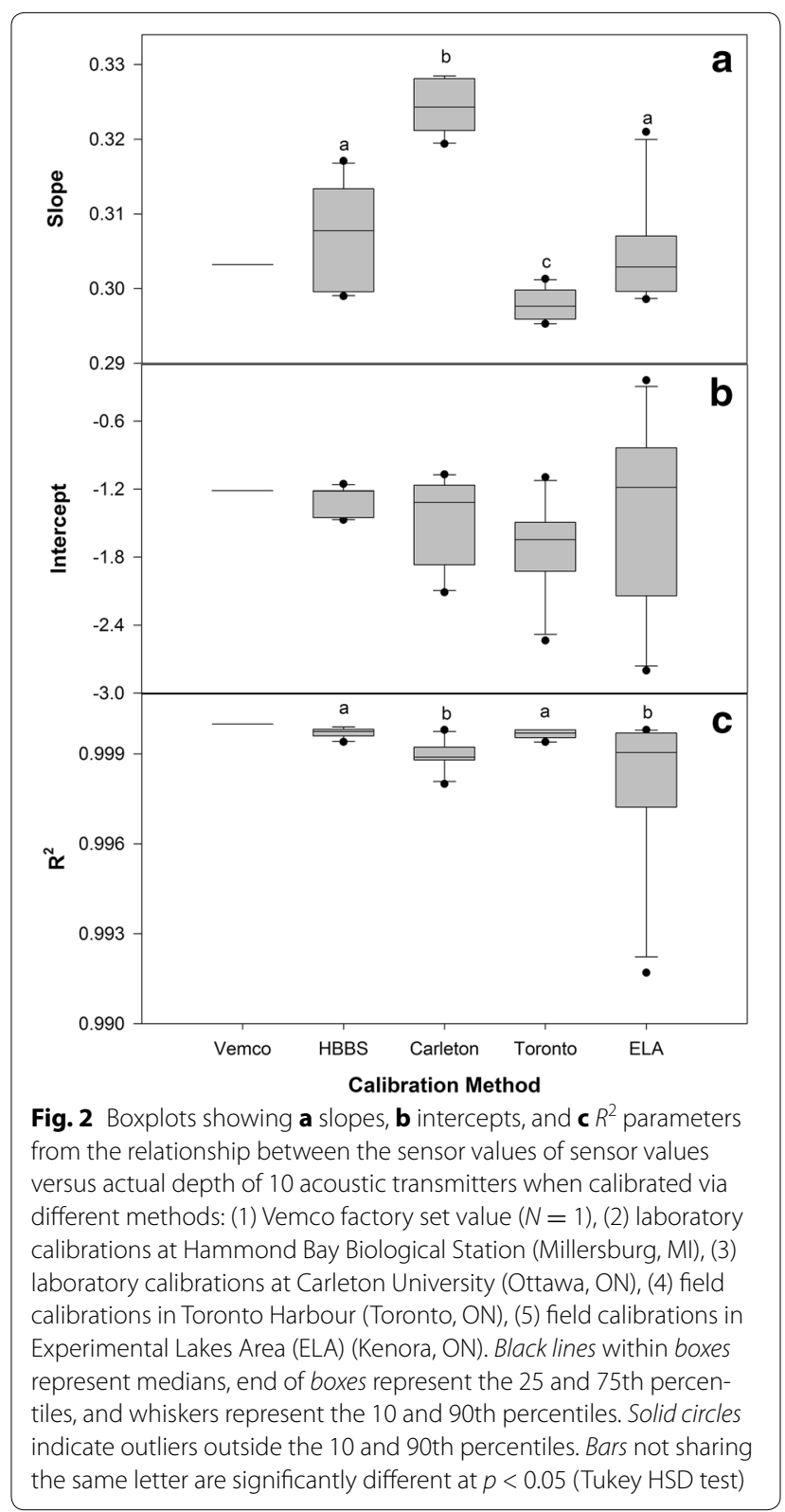

other three calibration methods (Tukey HSD test; all $p<0.0001)$. Slopes obtained from Toronto Harbour calibrations were significantly smaller than slopes obtained from calibrations performed in HBBS (Tukey HSD test; $p<0.0001$ ) and in ELA (Tukey HSD test; $p=0.011$ ). There was no effect of calibration method on intercept (LME; $F=2.167, d f=3, p=0.115$ ) (Fig. 2). However, calibration method had a significant effect on $R^{2}$ values (LME; $F=7.830, d f=3, p<0.0001$ ) (Fig. 2). $R^{2}$ values obtained from Carleton University calibrations were significantly lower than $R^{2}$ values obtained from calibrations performed in Toronto Harbour and HBBS (Tukey HSD test; $p<0.0001$ ). $R^{2}$ values obtained from 
ELA calibrations were significantly lower than $R^{2}$ values obtained from calibrations performed in Toronto Harbour (Tukey HSD test; $p=0.032$ ) and HBBS (Tukey HSD test; $p=0.019$ ). At a simulated depth of $68 \mathrm{~m}$ (where the greatest differences would occur), laboratory calibrations performed at Carleton University were estimated to report values $3.55-5.60 \mathrm{~m}$ deeper than factory calibrations, and laboratory calibrations performed at HBBS were estimated to report values $1.06 \mathrm{~m}$ shallower to $3.10 \mathrm{~m}$ deeper than factory calibrations. In addition, field calibrations performed in Toronto Harbour and ELA reported values $0.68-2.39 \mathrm{~m}$ shallower and $0.78 \mathrm{~m}$ shallower to $2.48 \mathrm{~m}$ deeper, respectively, than factory calibrations. This represents a total range of error of $9.15 \mathrm{~m}$ (3.55 m shallower to $5.60 \mathrm{~m}$ deeper than factory calibrations) across the four calibration methods.

\section{Calibrations at three different water temperatures}

There was a significant effect of water temperature on slope of calibration curves obtained in the laboratory (LME; $F=64.130, d f=2, p<0.0001$ ) (Fig. 3). Slopes obtained from all water temperatures differed significantly from each other (Tukey HSD; $p<0.0001$ ), with cold water calibrations having the smallest slopes and warm water calibrations having the largest slopes. There was also a significant effect of calibration water temperature on intercept (LME; $F=7.769, d f=2, p=0.004$ ) (Fig. 3). Intercepts obtained from calibrations performed in cold water temperatures were significantly lower than intercepts obtained from calibrations performed in warm water temperatures (Tukey HSD test; $p=0.001$ ). Finally, there was a significant effect of calibration water temperature on $R^{2}$ values (LME; $F=11.900, d f=2, p<0.0001$ ) (Fig. 3). $R^{2}$ values obtained from calibrations performed in cold water temperatures were significantly higher than $R^{2}$ values obtained from calibrations performed in cool water temperatures (Tukey HSD test; $p<0.0001$ ) and warm water temperatures (Tukey HSD test; $p=0.001$ ). At simulated depths of $68 \mathrm{~m}$, transmitters calibrated in Carleton University's pressure chamber with cold water reported values $2.22-4.96 \mathrm{~m}$ shallower than transmitters calibrated at room temperature. In addition, transmitters calibrated in Carleton's pressure chamber with warm water reported values $0.22 \mathrm{~m}$ shallower to $6.47 \mathrm{~m}$ deeper than transmitters calibrated at room temperature. This represents a total range of error of $11.43 \mathrm{~m} \mathrm{(4.96} \mathrm{m} \mathrm{shal-}$ lower to $6.47 \mathrm{~m}$ deeper than transmitters calibrated at room temperature) from 9 to $34{ }^{\circ} \mathrm{C}$.

\section{Quantifying error from temperature-driven changes in water density}

When using the pressure obtained from $20{ }^{\circ} \mathrm{C}$ water to estimate the depths of transmitters in 4 and $40{ }^{\circ} \mathrm{C}$ fresh

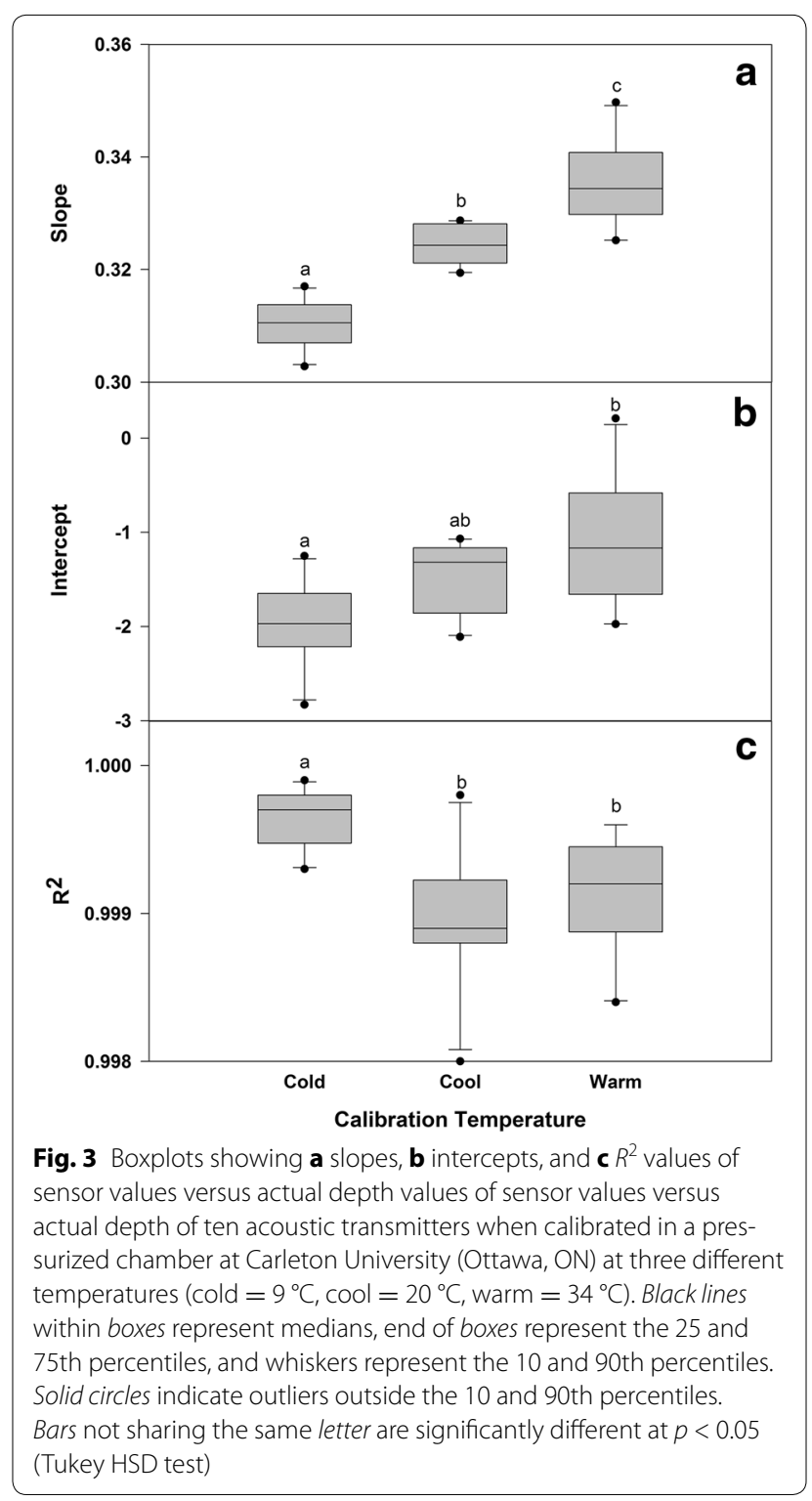

water, the equation reports depths of 67.88 and $68.41 \mathrm{~m}$, respectively, instead of the actual depths of $68 \mathrm{~m}$. Therefore, when using room-temperature pressures instead of pressures at the desired temperatures to calculate depths, transmitters at depths of $68 \mathrm{~m}$ in 4 or $40{ }^{\circ} \mathrm{C}$ fresh water can be reported $0.12 \mathrm{~m}$ shallower or $0.41 \mathrm{~m}$ deeper, respectively, than their actual depths (Table 1 ). This represents a maximum error of $0.006 \mathrm{~m}$ for each meter of depth.

\section{Quantifying error from salinity-driven changes in water density}

When using the pressure obtained from $20^{\circ} \mathrm{C}$ fresh water to estimate the depth of a transmitter in salt water, the 
Table 1 Error rates of acoustic transmitter pressure sensor output associated with three external effects (i.e., water temperature, salinity, and atmospheric pressure)

\begin{tabular}{|c|c|c|c|c|}
\hline External effect & Constant variables & Range of external effect & $\begin{array}{l}\text { Estimated } \\
\text { depth }(m)\end{array}$ & $\begin{array}{l}\text { Error }(m) \text { at a depth of } 68 \mathrm{~m} \\
\text { compared to actual depth }\end{array}$ \\
\hline \multirow{3}{*}{$\begin{array}{l}\text { Water } \\
\text { temperature }\left({ }^{\circ} \mathrm{C}\right)\end{array}$} & Salinity: fresh water & $\rho$ of $4^{\circ} \mathrm{C}$ fresh water $=999.9720 \mathrm{~kg} / \mathrm{m}^{3}$ & 67.88 & 0.12 shallower \\
\hline & Atmospheric pressure: standard & $\rho$ of $20^{\circ} \mathrm{C}$ fresh water $=998.2072 \mathrm{~kg} / \mathrm{m}^{3}$ & 68 & \\
\hline & & $\rho$ of $40^{\circ} \mathrm{C}$ fresh water $=992.2164 \mathrm{~kg} / \mathrm{m}^{3}$ & 68.41 & 0.41 deeper \\
\hline \multirow[t]{2}{*}{ Salinity $\left(\mathrm{kg} / \mathrm{m}^{3}\right)$} & Water temperature: room temperature & $\rho$ of fresh water $=998.2072 \mathrm{~kg} / \mathrm{m}^{3}$ & 68 & \\
\hline & Atmospheric pressure: standard & Salt water $\rho=1024.8103 \mathrm{~kg} / \mathrm{m}^{3}$ & 66.23 & 1.77 shallower \\
\hline \multirow{3}{*}{$\begin{array}{l}\text { Atmospheric } \\
\text { pressure }(\mathrm{Pa})\end{array}$} & Water temperature: room temperature & Low $P=87,000 \mathrm{~Pa}$ & 69.46 & 1.46 deeper \\
\hline & Salinity: fresh water & Standard $P=101,325 \mathrm{~Pa}$ & 68 & \\
\hline & & High $P=108,000 \mathrm{~Pa}$ & 67.32 & 0.68 shallower \\
\hline
\end{tabular}

The estimated depths were calculated based on the hydrostatic pressure for fresh water at $20^{\circ} \mathrm{C}$ and standard atmospheric pressure with the following formula: $P_{\text {total }}=P_{\text {atmosphere }}+P_{\text {fluid }}\left(P_{\text {fluid }}=\rho g h\right)$, where $\rho=$ water density $\left(\mathrm{kg} / \mathrm{m}^{3}\right), g=$ gravitational acceleration $\left(9.8 \mathrm{~m} / \mathrm{s}^{2}\right)$, and $h=$ depth $(\mathrm{m})$. For all evaluations of external effects on depth estimates, depths of $68 \mathrm{~m}$ (maximum depth of V16 transmitters) were used because errors would be most pronounced here (i.e., because changes in water density are cumulative with depth)

equation reports a depth of $66.23 \mathrm{~m}$ instead of the actual depth of $68 \mathrm{~m}$. Therefore, when using freshwater pressures instead of saltwater pressures to calculate depths, transmitters at depths of $68 \mathrm{~m}$ in salt water can be reported as much as $1.77 \mathrm{~m}$ shallower than their actual depth (Table 1). This represents an error of $0.026 \mathrm{~m}$ for each meter of depth.

\section{Quantifying error from changes in atmospheric pressure}

When using the hydrostatic pressure obtained from the standard atmospheric pressure to estimate the depth of a transmitter at low and high atmospheric pressures, the equation reports depths of 69.46 and $67.32 \mathrm{~m}$, respectively, instead of the actual depth of $68 \mathrm{~m}$. Therefore, when using the hydrostatic pressure obtained from the standard atmospheric pressure instead of the appropriate atmospheric pressures, transmitters at depths of $68 \mathrm{~m}$ at low or high atmospheric pressures can be reported $1.46 \mathrm{~m}$ deeper or $0.68 \mathrm{~m}$ shallower, respectively, than their actual depths (Table 1).

\section{Discussion}

Obtaining accurate calibration curves for pressure sensors on acoustic transmitters is critical for using them to infer swimming depth of fishes, particularly when studying vertical movements at fine-scales. Nonetheless, there are exceedingly few examples of where such factory-generated relationships have been validated. Errors in slopes and intercepts of calibration curves will affect estimated swimming depth in different ways; differences in intercepts will introduce constant error on all depth estimates, while error due to differences in slope will increase in magnitude with depth. For example, if we assume that the factory slope (i.e., 0.3032) and intercept (i.e., -1.2129 ) provide accurate estimates, a field- or lab-calibration-based intercept of -0.2129 will constantly report a depth $1 \mathrm{~m}$ deeper than factory estimates, whereas an intercept of -2.2129 will report a depth $1 \mathrm{~m}$ shallower at all depths. Equations with different slopes and identical intercepts will always report the same estimates at an ADC value of zero. However, a slope of 0.2032 will report a depth $1 \mathrm{~m}$ shallower relative to factory estimates at $10 \mathrm{~m}$ and will report a depth $10 \mathrm{~m}$ shallower than factory estimates at $100 \mathrm{~m}$. Conversely, a slope of 0.4032 will report a depth $1 \mathrm{~m}$ deeper than normal at $10 \mathrm{~m}$ and will report a depth $10 \mathrm{~m}$ deeper than normal at $100 \mathrm{~m}$.

Values obtained from laboratory calibrations led to maximal estimates of up to $5.60 \mathrm{~m}$ deeper than factoryderived estimates, whereas field calibrations reported maximal values of up to $2.48 \mathrm{~m}$ deeper and $2.39 \mathrm{~m}$ shallower than factory estimates. Field calibrations seem to provide depth estimates that were more consistent with factory-supplied calibration curves than laboratory calibrations. Reasons may include inaccurate pressure gauges or pressure not being held constant throughout the 10-min intervals. Given that Vemco reports an accuracy of $\pm 3.4 \mathrm{~m}$ for their transmitters, we did not find evidence that additional calibrations increased this accuracy. Overall, additional calibrations require considerable time and effort and may provide less accurate results. If all four calibrations gave similar slopes and intercepts that differed from Vemco, we would have concluded that additional calibrations were useful. However, because we observed variation among calibration methods and among transmitters, it is difficult to conclude which (if any) additional calibrations were beneficial. Further study is needed to understand why slopes and intercepts differed among calibration methods and how temperature influences sensor performance. 
Environmentally derived changes in hydrostatic pressure should be taken into consideration when interpreting depth data as they have an effect on pressure, which subsequently affects reported swimming depth (1.77 $\mathrm{m}$ shallower to $1.46 \mathrm{~m}$ deeper than standard conditions). Although errors associated with water temperature and salinity at a depth of $68 \mathrm{~m}$ may seem worrisome, it is important to remember that these errors would be smaller at shallower depths. This is because error increases cumulatively with depth. For example, a transmitter at a depth of $10 \mathrm{~m}$ will have an error ten times higher than the error at a depth of $1 \mathrm{~m}$ (i.e., error of $0.026 \mathrm{~m}$ at $1 \mathrm{~m}$ becomes an error of $0.26 \mathrm{~m}$ at $10 \mathrm{~m}$ ). Unlike water temperature and salinity, however, error associated with atmospheric pressure is constant with depth and will vary with time due to the passage of synoptic-scale high- and low-pressure weather systems. Day-to-day variations in atmospheric pressure are often on the order of $3 \%$, representing an apparent change in depth of $\sim 0.3 \mathrm{~m}$. Thus, changes in atmospheric pressure may be a dominant source of error for fish living in shallow waters, whereas water temperature and salinity may have greater effects at deeper depths. For detailed finescale pressure work in shallow wetlands or the edges of lakes, changes in atmospheric pressure can be measured so that apparent depths could be corrected. The time variation in atmospheric pressure is relatively slow and changes roughly diurnally, and so depths could be corrected if there is a nearby $(<15 \mathrm{~km})$ weather station or metrological buoy measuring barometric pressure. If this is not available, then a high-resolution pressure transducer should be mounted on shore. It seems also that temperature may directly affect the transducer mechanism of the pressure sensors because we observed a significant effect of temperature on both slope and intercepts of calibration curves produced in our laboratory pressure chamber, where temperature-derived changes in hydrostatic pressure would be negligible. Although some of these environmentally derived errors may seem negligible on their own, a combination of these effects may lead to much higher error (e.g., a cold water lake at high atmospheric pressure). Transmitters can be calibrated in relevant environmental conditions if these are relatively constant and different from factory conditions. For example, transmitters that will be implanted in fishes at high altitudes should be calibrated with atmospheric pressures that reflect this altitude. Correcting for external effects by calibrating transmitters in relevant environmental conditions should enable researchers to obtain lower error rates than those provided by the manufacturer. Unfortunately, some of these environmental conditions may vary significantly during the study period, making corrections quite challenging. Therefore, external effects should be taken into consideration when interpreting biological data, and fine-scale data should be interpreted with caution.

\section{Conclusions}

We focused our efforts on a single manufacturer and a small number of transmitters. Given that different manufacturers calibrate sensors in different ways, it is prudent to test factory calibrations, even if just to ensure that the sensors are working properly. It is beneficial to know if sensors are malfunctioning before being surgically implanted in fish. If malfunctioning transmitters are not detected prior to surgical implantation, they will report faulty data, which can lead to false interpretations.

Manufacturers may use a variety of pressure transducers in their devices. As such, it is not reasonable to assume that our findings extend across all depth-sensing transmitters, or even all those made by Vemco. However, the differences among calibration methods and the effects of external factors reported here are relevant to all depth-sensing transmitters. We did not find sufficient evidence to support the need for additional calibrations for all transmitters as they did not increase the accuracy of depth estimates; however, calibrating a subset of transmitters in a pressure chamber under different temperature conditions may be valuable for quantifying the effect of temperature on the sensor mechanism itself. To conclude, although experimental calibrations did produce calibration curves that differed significantly from the factory-supplied calibration curve, the lack of consistency among the various experimental calibrations suggests that it may be difficult to produce more accurate calibration curves experimentally without using a higher-end pressure chamber.

\section{Abbreviations}

ADC: analog to digital converter; ELA: experimental lakes area; HBBS: hammond bay biological station; HSD: honestly significant difference; LME: linear mixed-effects models; PVC: polyvinyl chloride; REML: restricted maximum likelihood.

\section{Authors' contributions}

MANV drafted the manuscript with help from NWRL and SJC. MANV, NWRL, TRB, and SJC participated in the design of the study. MANV, NWRL, TRB, PJB, and LCF carried out necessary field work (i.e., laboratory and field calibrations). $\mathrm{MHL}$ performed all statistical analyses. All authors read and approved the final manuscript.

\section{Authors' information}

Our team constitutes academic researchers, government scientists, and practitioners which collectively study the behavior of fish populations with acoustic telemetry, and subsequently implement changes in habitat management.

\section{Author details}

1 Fish Ecology and Conservation Physiology Laboratory, Department of Biology, Carleton University, 1125 Colonel By Drive, Ottawa, ON K1S 5B6, Canada. ${ }^{2}$ Vemco-Amirix Ltd., 20 Angus Morton Drive, Bedford, NS, Canada. ${ }^{3}$ Department of Fisheries and Wildlife, Michigan State University, 11188 Ray 
Rd., Millersburg, MI, USA. ${ }^{4}$ Freshwater Institute, Fisheries and Oceans Canada, Winnipeg, MB, Canada. ${ }^{5}$ Physical and Environmental Sciences, University of Toronto Scarborough, 1265 Military Trail, Toronto, ON M1C 1A4, Canada. ${ }^{6}$ National Institute of Aquatic Resources, Section for Freshwater Fisheries and Ecology, Technical University of Denmark, Vejlsøvej 39, 8600 Silkeborg, Denmark. ${ }^{7}$ Department of Fisheries and Oceans Canada, 867 Lakeshore Road, Burlington, ON L7R 4A6, Canada.

\section{Acknowledgements}

We would like to thank Lee Hrenchuk and Dave Callaghan from Experimental Lakes Area and the Toronto and Region Conservation Authority (TRCA) for assisting with field calibrations as well as the Great Lakes Fishery Commission for providing transmitters. Cooke is supported by NSERC (Strategic Grant and Discovery Grant) and the Canada Research Chairs Program. The authors or their agencies accept no responsibility regarding the safety of the calibration device described here and remind readers that working with pressurized chambers contains inherent risk.

\section{Competing interests}

The authors declare that they have no competing interests.

Received: 2 June 2015 Accepted: 11 December 2015

Published online: 11 January 2016

\section{References}

1. Blanchfield PJ, Tate LS, Plumb JM, Acolas ML, Beaty KG. Seasonal habitat selection by lake trout (Salvelinus namaycush) in a Canadian shield lake: constraints imposed by winter conditions. Aquat Ecol. 2009;43:777-87.

2. Block BA, Booth DT, Carey FG. Depth and temperature of the blue marlin, Makaira nigricans, observed by acoustic telemetry. Mar Biol. 1992;114:175-83.

3. Cooke SJ, Hinch SG, Wikelski M, Andrews RD, Kuchel LJ, Wolcott TG, Butler PJ. Biotelemetry: a mechanistic approach to ecology. Trends Ecol Evol. 2004;19:334-43.

4. Cooke SJ, Hinch SG, Lucas MC, Lutcavage M. Biotelemetry and biologging. In: Zale AV, Parrish DL, Sutton TM, editors. Fisheries techniques, vol. 3rd Edition. Bethesda: American Fisheries Society; 2012. p. 819-60.
5. Dagorn L, Bach P, Josse E. Movement patterns of large bigeye tuna (Thunnus obesus) in the open ocean, determined using ultrasonic telemetry. Mar Biol. 2000;136:361-71.

6. Donaldson MR, Hinch SG, Suski CD, Fisk AT, Heupel MR, Cooke SJ. Making connections in aquatic ecosystems with acoustic telemetry monitoring. Front Ecol Environ. 2014;12:565-73.

7. Gutowsky LFG, Harrison PM, Martins EG, Leake A, Patterson DA, Power $\mathrm{M}$, Cooke SJ. Diel vertical migration hypotheses explain size-dependent behaviour in a freshwater piscivore. Anim Behav. 2013;86:365-73.

8. Hanson KC, Cooke SJ, Suski CD, Niezgoda G, Phelan FJS, Tinline R, Philipp DP. Assessment of largemouth bass (Micropterus salmoides) behaviour and activity at multiple spatial and temporal scales utilizing a whole-lake telemetry array. Develop Fish Teleme. 2007;582:243-56.

9. Heupel MR and Webber DM. Trends in acoustic tracking: where are the fish going and how will we follow them? In: McKenzie JR, Parsons B, Seitz AC, Kopf RK, Mesa MG, Phelps Q, editors. Advances in fish tagging and marking technology. American Fisheries Society, Symposium 76. Bethesda; 2012. p. 219-231.

10. Hussey NE, Kessel ST, Aarestrup K, Cooke SJ, Cowley PD, Fisk AT, Harcourt RG, Holland KN, Iverson SJ, Kocik JF, Flemming JEM, Whoriskey FG. Aquatic animal telemetry: a panoramic window into the underwater world. Science. 2015;348(6240):1255642.

11. Lucas MC, Baras E. Methods for studying spatial behaviour of freshwater fishes in the natural environment. Fish Fish. 2000;1:283-316.

12. Pinheiro J, Bates D, DebRoy S, Sarkar D, R Core Team. nlme: linear and nonlinear mixed effects models. R package version 3.1-118. 2014. http:// CRAN.R-project.org/package=nlme. Accessed 28 Mar 2014.

13. R Development Core Team. R: a language and environment for statistical computing. R Foundation for Statistical Computing, Vienna, Austria. ISBN 3-900051-07-0. 2014. http://www.R-project.org. Accessed 28 Mar 2014.

14. Schurmann $\mathrm{H}$, Claireaux $\mathrm{G}$, Chartois $\mathrm{H}$. Changes in vertical distribution of sea bass (Dicentrarchus labrax L.) during a hypoxic episode. Hydrobiologia. 1998;371(372):207-13.

15. Simpfendorfer CA, Olsen EM, Heupel MR, Moland E. Three-dimensional kernel utilization distributions improve estimates of space use in aquatic animals. Can J Fish Aquat Sci. 2012;69:565-72.

16. Zuur AF, leno EN, Walker N, Saveliev AA, Smith GM. Mixed effects models and extensions in ecology with R. Berlin: Springer; 2009.

17. Zuur AF, leno EN, Elphick CS. A protocol for data exploration to avoid common statistical problems. Methods Ecol Evol. 2010;1:3-14.

\section{Submit your next manuscript to BioMed Central and we will help you at every step:}

- We accept pre-submission inquiries

- Our selector tool helps you to find the most relevant journal

- We provide round the clock customer support

- Convenient online submission

- Thorough peer review

- Inclusion in PubMed and all major indexing services

- Maximum visibility for your research

Submit your manuscript at www.biomedcentral.com/submit
() Biomed Central 